\title{
A study of the antigenic composition of the fragilis group of Bacteroides
}

\author{
K. M. ELHAG and T. O. ALKARMI* \\ Department of Microbiology, Faculty of Medicine, The University of Kuwait, PO Box 24923, Safat 13110, Kuwait
}

\begin{abstract}
Summary. Representative strains of 22 serotypes of the fragilis group of Bacteroides and four non-fragilis control strains of B. melaninogenicus, B. disiens, B. bivius and Fusobacterium nucleatum were tested by SDS-PAGE and immunoblotting with hyperimmune rabbit sera. SDS-PAGE showed 25 polypeptide bands but, after immunoblotting, 24 antigenic bands were observed in various combinations in all the strains. Three of these were detected only in the control strains, whereas six others were present in different combinations in all strains of the fragilis group but were not present in the controls. Cluster analysis of the antigenic bands showed that the controls were antigenically different from the fragilis group strains. Strains of the fragilis group from the same geographic localities grouped in single clusters; most faecal isolates and NCTC strains appeared separate. There was no correlation between the species of Bacteroides and their antigenic structure. SDS-PAGE with immunoblotting is a superior technique for typing the fragilis group of Bacteroides. Specific antigens have been identified which may be used in the serodiagnosis of infection with these organisms.
\end{abstract}

\section{Introduction}

The fragilis group of Bacteroides are the most commonly encountered anaerobic pathogens. ${ }^{1-4}$ They are antigenically heterogenous and serotyping has shown wide variation within the different species. ${ }^{5-8}$ Some serotypes prevail in certain hospitals which suggests their involvement in hospital cross-infections. ${ }^{9-10}$ Although typing schemes based on wholecell antigens have to some extent been helpful in understanding the epidemiology of the fragilis group of Bacteroides, they did not offer any new knowledge in terms of their virulence. Furthermore, no universal serotyping scheme for these bacteria has so far been developed.

Serological means for diagnosing infections with the fragilis group of Bacteroides have been sought without great success. ${ }^{11-13}$ The antigenic heterogeneity of the group ${ }^{5-8}$ and the geographic variation of their serotypes ${ }^{9-10}$ have hampered the selection of appropriate test antigens. It has been shown that the chance of detecting specific antibodies in patient sera improves with the use of a wider variety of test antigens. ${ }^{11,14,15}$ Furthermore, when lipopolysaccharide or whole bacterial cells were used as test antigens, false positive reactions were detected in sera from patients infected with organisms other than the fragilis group, as well as in sera from normal subjects. ${ }^{12,15-17}$

Received 3 July 1990; accepted 5 Dec. 1990.

*Correspondence should be sent to Dr T. Alkarmi, U.A.E. University, Faculty of Medicine and Health Sciences, Dept. of Medical Microbiology, P.O. Box 17666, Al-Ain, U.A.E.
We have analysed polypeptide antigens from different serotypes of the fragilis group of Bacteroides with hyperimmune rabbit sera. By cluster analysis of these antigens, we hope to identify the appropriate test antigens for use for serodiagnosis of infections with the fragilis group of Bacteroides and to provide some basis for a typing scheme for these organisms.

\section{Materials and methods}

\section{Bacterial strains}

Single representative strains of 22 distinct serotypes of the fragilis group of Bacteroides ${ }^{6,8,15}$ and four control strains of $B$. melaninogenicus, $B$. disiens, $B$. bivius, and Fusobacterium nucleatum were used. The strains and their source and place of isolation are shown in the table. They were identified according to: colony appearance; cell morphology; tolerance to bile and brilliant green; resistance to kanamycin $1000 \mu \mathrm{g}$, penicillin $2 \mathrm{U}$, colistin $10 \mu \mathrm{g}$, erythromycin $60 \mu \mathrm{g}$, rifampicin $15 \mu \mathrm{g}$ (Anaerodiscs; 57311-5731; bioMerieux); susceptibility to metronidazole $5 \mu \mathrm{g}$ (Oxoid; $195 \mathrm{~B})$; and analysis of end products of glucose metabolism by gas-liquid chromatography (Schimatzu Gas Chromatography GC 90, Schimatzu Corporation, Koyoto, Japan). They were also identified with the API 20A (API bioMerieux) system. ${ }^{18}$

\section{Preparation of bacteroides antisera}

Live cultures of the 22 strains of fragilis group serotypes were used for the production of antisera. 
Table. Bacterial strains

\begin{tabular}{|c|c|c|c|}
\hline $\begin{array}{c}\text { Strain } \\
\text { no. }\end{array}$ & Bacterial strain & Source of isolate & \\
\hline 1 & B. fragilis & NCTC 9343 & \\
\hline 2 & B. fragilis & NCTC 10584 & \\
\hline 3 & B. thetaeotaomicron & NCTC 10582 & \\
\hline 4 & B. vulgatus & NCTC 10583 & \\
\hline 5 & B. fragilis & NCTC 9344 & \\
\hline 6 & B. fragilis & NCTC 8560 & \\
\hline 7 & B. fragilis & NCTC 10581 & \\
\hline 8 & B. distasonis & ATCC 8503 & \\
\hline 9 & B. fragilis & Peritonitis exudate & BH \\
\hline 10 & $B$. fragilis & Peritonitis exudate & BH \\
\hline 11 & B. distasonis & Faeces & BH \\
\hline 12 & B. distasonis & Small intestine tissue & BH \\
\hline 13 & B. fragilis & Appendicectomy wound & $\mathrm{BH}$ \\
\hline 14 & B. fragilis & Cholecystectomy wound & BH \\
\hline 15 & B. fragilis & Blood & TH \\
\hline 16 & B. fragilis & Peritonitis exudate & MH \\
\hline 17 & B. fragilis & Appendicectomy wound & MH \\
\hline 18 & B. fragilis & Appendicectomy wound & MH \\
\hline 19 & B. distasonis & Appendicectomy wound & MH \\
\hline 20 & B. fragilis & Otitis media exudate & MH \\
\hline 21 & B. fragilis & Appendicectomy wound & MH \\
\hline 22 & B. fragilis & Vagina & MH \\
\hline 23 & B. melaninogenicus & Vagina & Mat \\
\hline 24 & B. bivius & & \\
\hline 25 & B. disiens & Vagina & Mat \\
\hline 26 & F. nucleatum & Otitis media exudate & MH \\
\hline
\end{tabular}

NCTC $=$ National Collection of Type Culture, London; ATCC $=$ American Type Culture Collection; $\mathrm{BH}=\mathrm{St}$ Bartholomew's Hospital, London; TH $=$ St Thomas' Hospital, London; MH=Mubarak Al-Kabeer Hospital, Kuwait; Mat=Maternity Hospital, Kuwait.

These were raised in New Zealand White rabbits as described by Elhag and Tabaqchali; ${ }^{11} 2 \mathrm{ml}$ of each antiserum were pooled and used for screening.

\section{Sodium dodecyl sulphate-polyacrylamide gel electrophoresis (SDS-PAGE)}

SDS-PAGE was performed as described by Alkarmi et al. ${ }^{19} \mathrm{~A}$ separating gel of acrylamide (Sigma) $12 \%$ $(30 \% \mathrm{~T}, 2.65 \% \mathrm{C})$ and a stacking gel of $5 \%$ were used. Lyophilised Bacteroides strains were dissolved ( $2 \mathrm{mg} /$ $\mathrm{ml}$ ) in sample buffer (pH 6.8) and kept in a boiling water bath for $5 \mathrm{~min}$ and then $25 \mu \mathrm{l}$ of the sample containing $25-80 \mu \mathrm{g}$ of protein was applied to each well in the stacking gel and electrophoresed at $5 \mathrm{~mA} /$ gel slab until the sample had reached the separating gel and then at $30 \mathrm{~mA} / \mathrm{gel}$ slab for a further $2-3 \mathrm{~h}$.

\section{Protein determination}

The amount of protein in the suspensions of bacteroides antigens was determined by the BioRad protein assay (BioRad, Cat No. 500-0001, CA, USA) performed according to the manufacturer's directions. The dye reagent (1 vol) was diluted with double distilled water (DDW) (4 vol), filtered through Whatman No. 1 filter paper and mixed with the protein sample solution $(20 \mu \mathrm{l} / \mathrm{ml}$ of the diluted dye reagent). The mixture was left at room temperature for $10 \mathrm{~min}$ and absorbance at $595 \mathrm{~nm}$ was then measured in a spectrophotometer (DU-7; Beckman Instruments, CA, USA). A protein standard curve was prepared with bovine plasma albumin.

\section{Electrophoretic transfer of protein to nitrocellulose paper (NCP)}

The method of Towbin et al. ${ }^{20}$ was followed with slight modification for the characterisation of polypeptides transferred from polyacrylamide gels to NCP. Samples containing crude bacteroides antigens were first subjected to SDS-PAGE as described above and then transferred to NCP. The NCP blots were then incubated in bovine serum albumin (BSA) $3 \%$ in Trissaline buffer ( $\mathrm{pH} 7.4)$ for $1 \mathrm{~h}$ at $40^{\circ} \mathrm{C}$ in a circulating water bath, rinsed in Tris-saline buffer, and incubated at $4^{\circ} \mathrm{C}$ with rabbit anti-bacteroides sera (which had been diluted 1 in 50 in Tris-saline buffer) and preadsorbed with normal mouse and guinea-pig liver and kidney tissue powder. After overnight incubation, the NCPs were washed in Tris-saline buffer and reincubated for $1 \mathrm{~h}$ at $25^{\circ} \mathrm{C}$ with peroxidase-conjugated goat anti-rabbit IgG (United States Biochemicals, CA, USA) diluted 1 in 250 in Tris-saline buffer. They were then washed with Tris-saline buffer and incubated with the substrate (3.3' diaminobenzidine tetrahydrochloride $0.3 \mathrm{mg} / \mathrm{ml}$ and fresh $\mathrm{H}_{2} \mathrm{O}_{2} 0.005 \%$ in $50 \mathrm{~mm}$ Tris buffer, $\mathrm{pH} \mathrm{7.5)}$. The intensity of the reaction was stopped by immersing the sheets in buffer and then in DDW. To compare immunogenic polypeptides with non-immunogenic ones, a duplicate NCP from each gel was stained with Amido black $0.1 \%$ in acetic acid $5 \%$. The resultant bands were overlapped and compared with those which appeared after immunoperoxidase staining.

\section{Molecular weight estimation}

The mol. wt of bacteroides antigens was determined by SDS-PAGE with mol. wt markers of 66-14 Kda (Sigma). Rf values were used for mol. wt estimation.

\section{Scanning of gels and NCPs}

The gels and NCPs were scanned with a Hoefer GS-300 scanning densitometer with GS-36S data system (Hoefer Scientific Instruments, CA 94107, USA). Individual peaks were identified, the RF values were determined and the mol. wts were calculated. Scans were compared with overlay software facility for data integration and analysis.

\section{Statistical methods}

The SPSSX statistical software package was used to compute proximities and to construct the dendrogram. ${ }^{21}$ Twenty-four variables were defined to denote the presence or absence of the 24 polypeptide bands among the strains. The proximities between the strains were measured by the Jaccard similarity measure, in 
which the similarity ratio was in the range $0-1$ and the higher the ratio, the greater the similarity between strains.

\section{Results}

The polypeptide bands demonstrated by SDSPAGE, combined with the antigenic bands detected in the NCP, are illustrated in the diagram (fig. 1). Various combinations of 25 polypeptide bands were observed in SDS-PAGE gels from all the bacterial strains tested, at mol. wts from $102.3 \mathrm{Kda}$ to $10.8 \mathrm{Kda}$. The number ranged from eight bands in strains 5 and 6 to 20 bands in strain 22 . After immunoblotting, 24 bands, with mol. wts from $82 \mathrm{Kda}$ to $10.8 \mathrm{Kda}$ were detected; 21 of these were present in the fragilis group strains, and the remaining three, of mol. wts $51 \cdot 6,28 \cdot 6$ and $15.4 \mathrm{Kda}$, were found only in the control strains. Each strain of the fragilis group possessed a mosaic of antigen composition ranging from seven to 15 antigenic determinants. The lowest number of antigens appeared in strains 5, 6, 7 and 20 and the highest in strains 17 and 19. Six antigenic bands with mol. wts $82,40 \cdot 5,37,27 \cdot 8,16$ and $10 \cdot 8 \mathrm{Kda}$, not detected in any of the control organisms, were present in various combinations in each strain of the fragilis group of Bacteroides. It was also observed that certain bands which appeared in SDS-PAGE were antigenic in some strains but not in others (fig. 1).

Similarities between strains of the fragilis group of Bacteroides and other anaerobic gram negative bacilli are shown in a dendrogram based on these data (fig. 2). B. melaninogenicus, B. bivius, $B$. disiens and $F$. nucleatum strains were each identified in separate clusters, distinct from the fragilis group clusters. Four clusters (pairs) of strains with high similarity $(78 \%)$ were identified. These clusters comprised strains 8 and 10 , strains 17 and 19 , strains 21 and 22 and strains 3 and 9. At a lower similarity ratio of $70 \%$, strain 18 joined strains 17 and 19 to form a larger cluster.
Another cluster containing strains 14,15 and 16 was identified at a lower similarity ratio.

Similarity between strains from certain geographical localities was observed, e.g., strains 17,18 and 19 with a similarity of $70 \%$ and strains 21 and 22 with $78 \%$ similarity were isolated from Kuwait. Strains 14 , 15 and 16 were isolates from London and formed a separate cluster. Faecal isolates and most NCTC strains did not join in any cluster. On the other hand, correlation was not observed between the species of Bacteroides isolates and their antigenic structure, as strains belonging to different species were present in the same cluster, e.g., strains 3 and 9,8 and 10 , and 17 and 19.

\section{Discussion}

In this study we analysed the antigenic components of different serotypes of the fragilis group of Bacteroides, in an attempt to identify appropriate antigens for serodiagnosis of infection with these organisms and possibly to utilise the antigenic pattern in a typing scheme. The immunogenicity of the various bands varied with different strains; bands with the same mol. wt were immunogenic in some strains and not in others (fig. 1). This reflects the different chemical composition and variation of the antigenic structure of bands appearing at the same mol. wt level. Therefore, SDS-PAGE patterns alone should not be used as a criterion for typing Bacteroides spp.

Immunoblots of SDS-PAGE can possibly be used in the diagnosis of infections with the fragilis group of Bacteroides but emphasis should be on those bands that appeared in various proportions in each of the fragilis group strains and were absent from the other gram-negative anaerobic bacilli. It has been shown before that members of the fragilis group of Bacteroides possess specific antigens, not shared with other gramnegative anaerobes. ${ }^{6,8}$ Such purified group-specific antigens are appropriate for serodiagnostic tests.

Strain no.

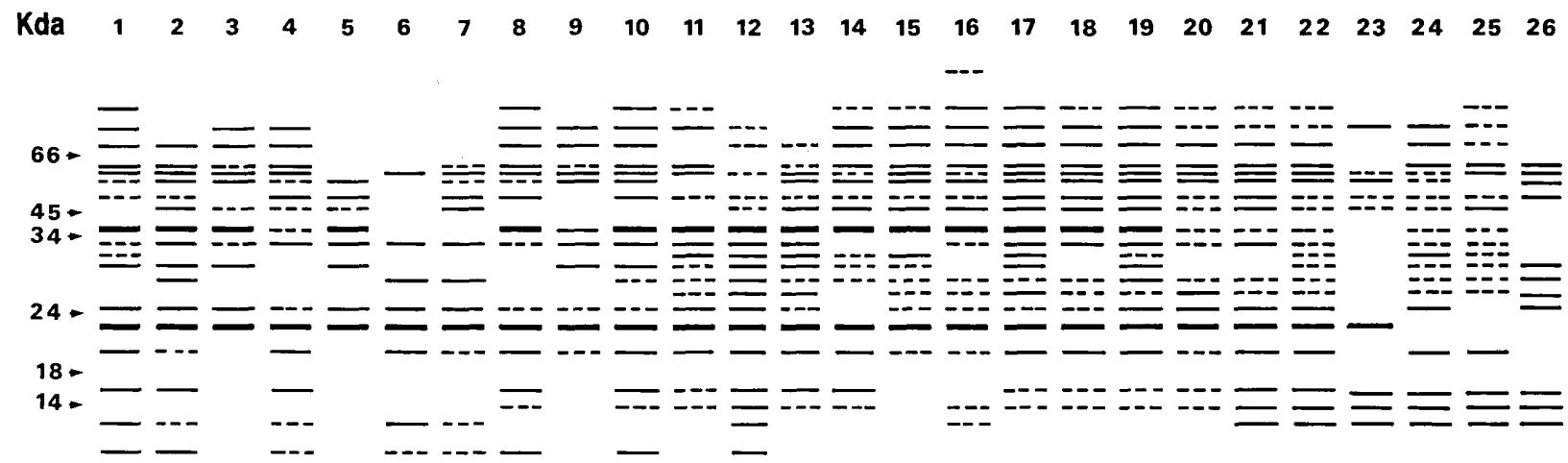

Fig. 1. A diagram illustrating the electrophoretic and immunoblot patterns of 22 strains of different serotypes of the fragilis group of Bacteroides (1-22), B. melaninogenicus (23), B. bivius (24), B. disiens (25), F. nucleatum (26) and the mol. wt standards. Bands shows as broken lines (_ _ _ ) have not been detected by immunoblotting on the NCP. All the other bands, represented by solid lines (- - $)$ have been identified as antigenic on the NCP. 


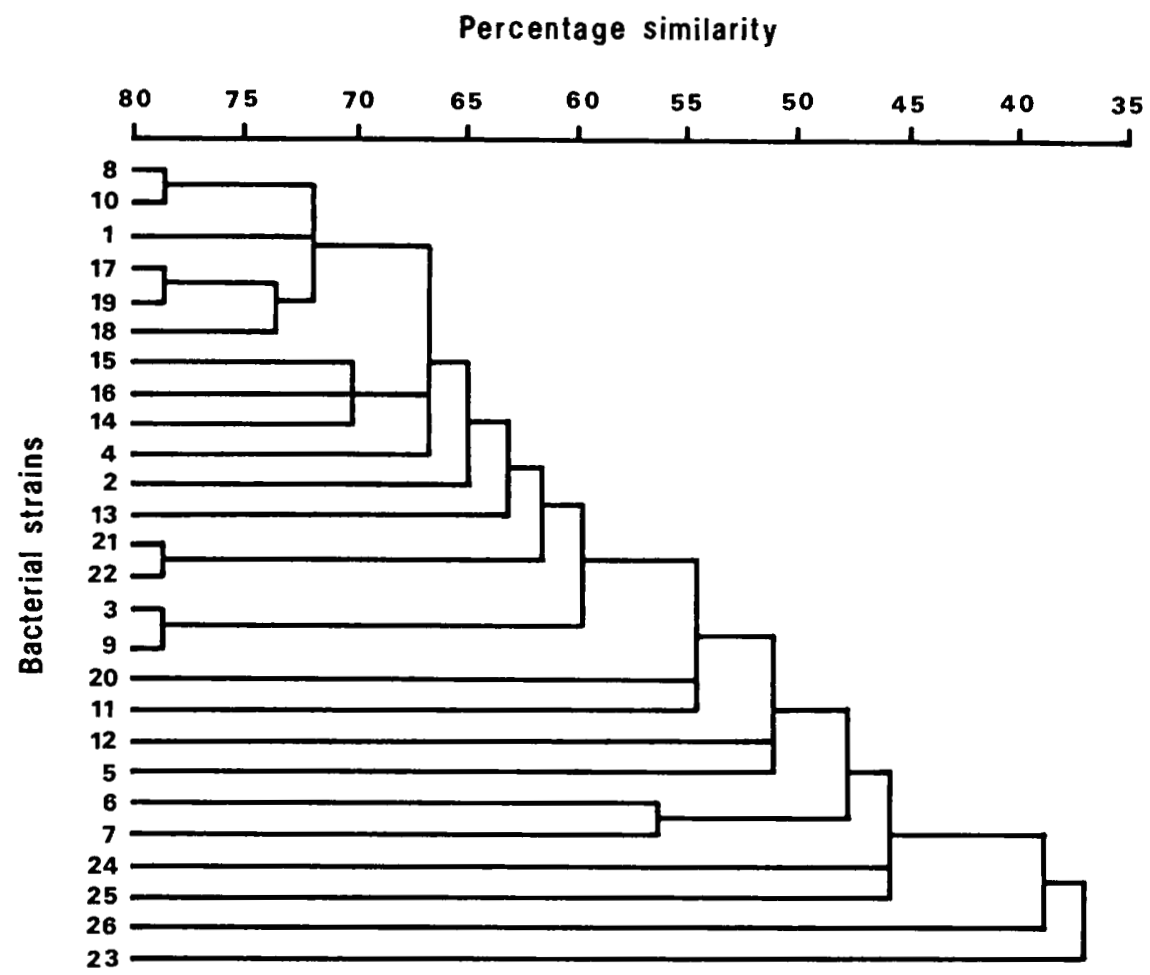

Fig. 2. Dendrogram of showing the similarity between 22 isolates of different serotypes of the fragilis group of Bacteroides (1-22), B. melaninogenicus (23), B. bivius (24), B. disiens (25) and F. nucleatum (26), based on their immunoblot patterns on NCP.

These antigens are expected to react with a wide range of patient sera, as has been shown in our previous study, in which patient and control sera were tested against the same serotypes. ${ }^{15}$ Nevertheless, these antigens will have to be tested against sera from infected patients and normal subjects to confirm these findings. We are now investigating the antigenic composition of each strain individually, based on reactivity with sera from infected patients and normal subjects.

Although most of the antigenic bands were present in all the serotypes, they occurred in various combinations, allowing grouping of antigenically similar Bacteroides strains into clusters (fig. 2). Such serological variation of $B$. fragilis strains, based on outermembrane and cell proteins, was demonstrated by Cherniak et al. ${ }^{22}$ The control organisms were found to be completely different from the fragilis group of Bacteroides, a finding which confirms earlier reports that the fragilis group are serologically distinct from other gram-negative anaerobes. ${ }^{6,8}$

Furthermore, the grouping of different species of Bacteroides in one cluster, such as strains 3 and 9, confirms earlier reports that there is no correlation between the species and the antigenic structure of these organisms. ${ }^{9}$ On the other hand, the detection of common antigens in the NCP, shared by most strains of the fragilis group, contradicts our earlier findings, when we reported only few cross-reactions between the strains tested. ${ }^{6,8}$ An interesting finding was that some Bacteroides strains from the same geographic location grouped in the same clusters. This is similar to our earlier results, although our previous work was based on different serological methods and, perhaps, different antigenic determinants. ${ }^{9,10}$

Previous typing schemes, based on whole cell antigens showed some success in understanding the epidemiology of $B$. fragilis, ${ }^{9,10}$ but they had limited value in differentiating virulent from avirulent strains. $^{9,10,23}$ However, the present findings have enabled us to identify unique antigenic components in the various strains of the fragilis group of Bacteroides, which may possibly be used as epidemiological or virulence markers.

No doubt SDS-PAGE and immunoblotting are methods of typing the fragilis group of Bacteroides superior to those previously described. However, a more comprehensive typing scheme based on protein antigens, as well as other antigenic cellular components, such as polysaccharides and lipopolysaccharides $^{7,24}$ is our future aim. Only then will it be possible to understand more fully the pathogenicity and epidemiology of this group of bacteria.

This work was supported by Kuwait University Research Council (grants nos MI 062 and MI 056). We thank Dr A. Senthilselvan for statistical analysis, Miss Fatima Hussain Abdelgalil for technical assistance and Mr Mohamed Sidiq for the drawings.

Editor's note. This report would not normally have been published without photographs of the SDS-PAGE gels, but the original photographs were lost, presumed destroyed, during the invasion of Kuwait in August 1990. In these extenuating circumstances, the editors have decided to publish the report with only the composite drawing of the protein profiles because the work reported is a valid contribution to the subject. 


\section{References}

1. Moore WEC, Cato EP, Holdeman LV. Anaerobic bacteria of the gastrointestinal flora and their occurrence in clinical infections. J Infect Dis 1969; 119: 641-649.

2. Gorbach SL, Bartlett JG. Anaerobic infections. $N$ Engl J Med 1974; $290: 1177-1184$

3. McGowan K, Gorbach SL. Anaerobes in mixed infections. $J$ Infect Dis $1981 ; 144$ : 181-186.

4. Elhag KM, Bahar AM, Alwan MH, Mahajan KK, Sherif RA, Senthilselvan A. Anaerobes in surgical infections in Kuwait : a multicenter study on 379 patients. Med Principles Pract 1989; $1: 44-51$.

5. Lambe DW, Moroz DA. Serogrouping of Bacteroides fragilis subsp. fragilis by agglutination test. J Clin Microbiol 1976; 3: $586-592$.

6. Elhag KM, Bettelheim KA, Tabaqchali S. Serological studies of Bacteroides fragilis. J Hyg 1977; 79: 233-241.

7. Babb JL, Cummins CS. Relationships between serological groups and deoxyribonucleic acid homology groups in Bacteroides fragilis and related species. J Clin Microbiol 1981 ; 13 : 369-379.

8. Elhag KM, Tabaqchali S. A study of the surface and somatic antigens of Bacteroides fragilis. J Hyg 1978; 80 : 439-449.

9. Elhag KM, Tabaqchali S. The distribution of Bacteroides fragilis serotypes amongst clinical strains. J Hyg 1978; 81 : 89-97.

10. Elhag KM, Senthilselvan A. A serogrouping scheme for the study of the epidemiology of Bacteroides fragilis. $J \mathrm{Med}$ Microbiol 1988; 27: 199-205.

11. Ross CAC, Gilmore RF. Serological diagnosis of Bacteroides fragilis infections by a complement fixation test. $J$ Clin Pathol 1978; 31 : 1083-1084.

12. Rissing JP, Buxton TB, Edmondson HT. Detection of specific IgG antibody in sera from patients infected with Bacteroides fragilis by enzyme-linked immunosorbent assay. $J$ Infect Dis 1979; 140: 994-998.

13. Okubadejo OA, Lightfoot NF, Hewitt WG. Diagnosis of Bacteroides fragilis infection with counter-immunoelectrophoresis. J Clin Pathol 1978; 31 : 1078-1082.
14. Paavonen J, Valtonen VV, Kasper DL, Malkamäki M, Mäkelä PH. Surgical evidence for the role of Bacteroides fragilis and Enterobacteriaceae in the pathogenesis of acute pelvic inflammatory disease. Lancet 1981; 1:293-295.

15. Elhag KM, Bahar AM, Mahajan KK. Difficulties in the serodiagnosis of infection with the fragilis group of Bacteroides. J Med Microbiol 1987; 24: 125-131.

16. Danielsson D, Lambe DW, Persson S. Immune response to anaerobic infections. In: Ballows A, De Haan RM, Dowell VR, Gurse LB (ed) Anaerobic bacteria: Role in disease. Springfield IL, Charles C. Thomas. 1974: 173-191.

17. Hofstad T. Antibodies reacting with lipopolysaccharides from Bacteroides melaninogenicus, Bacteroides fragilis and Fusobacterium nucleatum in serum from normal human subjects. $J$ Infect Dis 1974; 129: 349-352.

18. Holdeman LV, Cato EP, Moore WEC (eds). Anaerobe Laboratory manual, 4th edn. Anaerobe Laboratory, Virginia Polytechnic Institute and State University, Blacksburg, VA. 1977.

19. Alkarmi T, Ali-Khan Z, Zarkados C. Characterization of amyloid protein from chronic hydatid mice: isolation, purification and amino acid analysis. Exp Mol Pathol 1985; 45: $142-159$.

20. Towbin H, Staehelin T, Gordon J. Electrophoretic transfer of proteins from polyacrylamide gels to nitrocellulose sheets: procedures and some applications. Proc Natl Acad Sci USA $1979 ; 76: 4350-4354$.

21. Norusis MJ. Cluster analysis; proximities. In: SPSSX: Advanced statistics guide. New York, McGraw-Hill Company. 1985: 165-191 and 462-467.

22. Cherniak R, Lombard GL, Dowell VR. Immunochemical evidence of multiple serotypes of Bacteroides fragilis. J Clin Microbiol 1979; 9:699-704.

23. Romond $\mathrm{Ch}$, Beerens $\mathbf{H}$, Wattre $\mathbf{P}$. Serological identification of bacteroides connected with their pathogenicity. Arch Roum Pathol Exp Microbiol 1972; 31 : 351-355.

24. Kasper DL. The polysaccharide capsule of Bacteroides fragilis subspecies fragilis: immunochemical and morphologic definition. $J$ Infect Dis 1976; 133: 79-87. 